\title{
LA PUBLICIDAD EN LA WEB: HACIA EL PATROCINIO Y EL BANNER NARRATIVO AUDIOVISUAL.
}

\author{
Claudia Rausell Köster \\ Universidad de Alicante \\ claudia.rausell@ua.es
}

Resumen: La publicidad en la web seguirá evolucionando a la misma velocidad que lo ha hecho hasta abora. En primer lugar la actual incongruencia entre el tipo de contenidos existentes en la web y las manifiestas preferencias del colectivo de usuarios más numeroso, provocará el auge del patrocinio que se centrará en las páginas y portales dedicadas a la información de calidad y al entretenimiento. En segundo lugar el lógico y progresivo descenso del click-through y la previsible coexistencia durante un tiempo bastante amplio de las dos velocidades en las conexiones de Internet, incrementará la inversión en banners y éstos, ante la imposibilidad de ganar en espectacularidad visual a través del preciosismo fotográfico, tenderán a desarrollar la narración audiovisual.

Palabras clave: Publicidad, internet, patrocinio, banners, narración audiovisual.

Abstract: Advertising in the web will develop at the same speed than up to now. In the first place the actual incongruity of the type of content that the web offers and the demands of its major audience, will lead to an increase of sponsorship, mainly of pages focused on high quality information and entertainment. Secondly, the logical and progressive decrease of click-through and the foreseable coexistence during quite a long period of the two speeds in the internet conexion, will augment the investment on banners, which, taking into account the impossibility of major visual spectacularity through elaborate photography, will tend to develop audiovisual narrative.

Keywords: Advertising, internet, sponsorship, banners, audiovisual narrative. 


\section{Algunos datos sobre la red: contenidos y usuarios}

En primer lugar cabría señalar que los usuarios de Internet pertenecen mayoritariamente a la clase alta y media. El $36.3 \%$ de los hogares espańoles tiene ordenador, pero sólo un $18^{\prime} 7 \%$ tiene conexión a Internet (AIMC/EGM 2003a: 56) y el 3'9\% tiene banda ancha (Telefónica 2002: 69), mientras que la clase baja, un 33\% de la población, tiene un sólo televisor, no tiene coche, ni vídeo, ni por supuesto ordenador. En segundo lugar, la audiencia de Internet es básicamente una audiencia joven y ha ido creciendo en los últimos años más por la franja inferior que por la de arriba, lo que indica que es probable que crezca por la franja superior muy lentamente, a medida que los internautas actuales se hacen más mayores. El 66'1\% de los usuarios de Internet de Abril/Mayo del 2003 es menor de 35 ańos e incluso el grupo más nutrido es la franja más joven: el $37 \%$ de los internautas tienen entre 14 a 24 años, el 29,1 $\%$ entre 25 y 34 años. A medida que aumenta la edad disminuye su presencia en Internet: el 18'8\% tiene de 35 a 44 años y el $10^{\prime} 9 \%$ de 45 a 54 ańos (AIMC/EGM 2003b). Y en tercer lugar, atendiendo a su utilización de Internet, existen básicamente dos tipos de usuarios: los adolescentes y jóvenes que usan el e-mail y buscan diversión: frecuentan los Chats y páginas de juegos y entretenimiento, están más abiertos a vagabundear y probar itinerarios alternativos y son más propensos a responder a los reclamos publicitarios (siempre y cuando impliquen interactividad y diversión); y los adultos jóvenes (mayores de 25 años), que la usan cada vez más para buscar información y servicios: compra de entradas para conciertos, reservas de vuelos, consulta del estado de su cuenta bancaria, del BOE, de como realizar la declaración de la renta, o búsquedas de información sobre cualquier tema que sea de su interés y para lo cual antes se recurría a la enciclopedia o al listín telefónico: los síntomas de una enfermedad, las actividades de una empresa o institución etc.

Según su contenido la mayor parte de las páginas webs son informativas o pseudo informativas, le siguen las comerciales -aun- 
que siendo puristas podemos considerar que toda página web es publicidad puesto que es el propio individuo, empresario o institución quien selecciona y redacta el contenido de la misma (Rauscll 2003: 127-129)-y existen muy pocas dedicadas al entretenimiento: juegos, Chats, relatos. Entre éstas sin embargo destacan los portales, que ofrecen servicios de valor añadido: Chats, foros, juegos, información, horóscopo, correo electrónico y son con distancia los más frecuentados, durante el mes Abril/Mayo 2003, Yahoo y Terra recibieron 4.059 y 3613 miles de visitas respectivamente frente a las 1079 o 992 de El País o el Marca (AIMC/EGM 2003b).

2. Las webs comerciales y las acciones publicitarias: one click, rich media, beyond the banner, e-mail marketing y acciones integradas

Los contenidos y la tecnología disponible de cualquier medio determinan $y$ son determinados por la publicidad, pero en Internet la influencia de esta última es aún mayor. La temprana presencia de la publicidad en un medio todavía en evolución, ha influido de manera determinante en el desarrollo de nuevas tecnologías aplicadas al medio: los sistemas de compresión de imagen y audio no se hubieran implantado tan rápidamente de no ser por la presión del discurso publicitario que necesita ofrecer mensajes seductores, sorprendentes y espectaculares, así como ha sido la publicidad quien ha impulsado la aparición de contenidos de entretenimiento y de carácter lúdico mucho más adecuados para sus objetivos.

Según el Tercer Estudio de Agemdi sobre Marketing directo y publicidad en Internet del 2002 (AGEMDI 2002), todas las empresas españolas de más de 1000 empleados, y el $87 \%$ de las que tienen entre 200 y 500 tienen página web. En total un $39 \%$ del conjunto de las empresas españolas tienen página web (Barcelona Activa SA 2002), pero el $71 \%$ de las inversiones publicitarias a nivel mundial ha recaido en el banner (Online Publishers Association 2003). Según la función publicitaria prevalente de la página web comercial podemos distinguir: las páginas webs corpo- 
rativas, las promocionales de producto-marca, los portales, y las dedicadas al comercio electrónico o a la creación de comunidades. La página web corporativa ofrece básicamente información sobre la empresa, mientras la página promocional, con el propósito de seducir más que de informar, suele centrarse en un sólo producto o en una sola campaña de la marca y se asemeja a la función que desempeńan los espots publicitario. El acometido principal del portal es el de ser una página de paso que ofrece toda una serie de servicios (en la mayoría de los casos de entretenimiento o relacionados con éste), la de las webs de comercio electrónico, que no están todavía muy desarrolladas en España, es vender a través de Internet, y las páginas webs de generación de comunidades tienen como función principal ofrecer ciertos juegos y contenidos lúdicos para atraer a los internautas, recabar información sobre éstos y fidelizarlos.

Pero la página web comercial por muy elaborada y efectiva que resulte, por mucho que se haya dado de alta en los diferentes buscadores o incluso pagado para que aparezca en primer lugar, por sí sola no es suficiente para publicitar una marca o producto, puesto que en la vasta red, compite con un sin fin de otras páginas webs comerciales e informativas que pueden atraer la atención del internauta. Según los últimos estudios de DoubleClick Inc (2002) el uso de buscadores ha decaído progresivamente a medida que los internautas se hacen más expertos en la navegación. La página web sede o site comercial no es más que el local, pero hay que publicitarse en otros espacios para ir a buscar a los consumidores y atraerlos a la sede. Surgen así las acciones publicitarias. Con respecto a los distintos tipos de éstas, la imprecisión y confusión terminológica es enorme. Por un lado se encuentran las acciones publicitarias como el e-mail marketing que, como su nombre indica, se realizan a través del e-mail, y por otro las demás, que se realizan a través de la web. Entre estas últimas podemos diferenciar las acciones publicitarias puntuales, de las campañas integradas que implican varias acciones separadas en el tiempo o en el espacio, pero relacionadas entre sí. Entre las primeras se distinguen tres categorías: el One 
Click, el Rich Media y el Beyond the Banner, distinción que genera grandes discrepancias conceptuales. Su significado ha variado a lo largo del tiempo pero tampoco hoy se aplican los mismos criterios para su definición, ni entre los teóricos, ni entre las empresas que ofrecen estos servicios.

Aunque no hay unanimidad resulta operativo considerar que el One Click y el Rich Media son banners, anuncios que ocupan un espacio predeterminado y fijo en el interior de la página web que los alberga (al modo de los anuncios en prensa), mientras que el término Beyond the Banner alude a aquellos anuncios que aunque asociados a una página determinada, en lugar de ubicarse en el interior de la página web, se superponen a la misma (pop ups, layers, microsites etc). El Rich Media se diferencia del One Click por la tecnología que utilizan y las formas expresivas que permiten. El One Click es un banner cuya función principal es enviar al internauta a la página sede comercial o microsite, utiliza sólo las imágenes gif y jpg, se limita a las posibilidades expresivas del HTML, soporta muy poca calidad de imagen o animación (básicamente alternancia de imágenes fijas), no tiene audio ni interactividad (a excepción hecha del reenvío a la página sede), mientras que el Rich Media utiliza toda una serie y combinación de programas que le permiten introducir imágenes con calidad fotográfica o en movimiento (animaciones o vídeo), así como audio y interactividad. Los programas más utilizados son Macromedia Flash, Unicast, Eyeblaster y Bluestreak que permiten comprimir la imagen fija o en movimiento así como el audio mediante fórmulas matemáticas, de forma que tardan menos en descargarse y pueden a su vez combinarse con la descarga en el navegador de usuario de programas Java o los applets Active X de Microsoft que permiten introducir interactividad y recabar información del usuario.

En el lenguaje corriente el término banner viene a significar algo así como "todo anuncio que no es un pagina web comercial con un enlace a la página comercial sede, que previo pago o por intercambio se colocan en páginas webs ajenas para atraer hacía sí 
la clientela. En un primer momento y sobrevalorando el reclamo de la interactividad se consideraba que la función del banner era remitir al usuario a la página de la empresa, sin embargo la experiencia y las nuevas generaciones de banner demuestran que esto no tiene por qué ser así. Al igual que los anuncios en medios tradicionales su función puede ser la de simplemente posicionar la marca en el recuerdo del consumidor, crear una imagen de marca, otorgarle valor añadido, lanzar ofertas etc. Así pues pueden enlazar con la página web madre, o no hacerlo, o simplemente enlazar con microsites expresamente creadas para ellos. Recientes estudios (DoubleClick 2002) demuestran que el banner puede ser efectivo sin haber logrado que el usuario clique para acudir a la página madre, lo que ha provocado la polémica todavía abierta de si se debe establecer el precio del banner en función de las veces que el usuario accede a través de él a la página madre o microsite o si por el contrario debe ser en función de las visitas que la página anfitriona ha recibido.

Tanto el banner como la página web y al igual que los anuncios en los medios tradicionales de comunicación masiva, tienen la posibilidad de identificar y segmentar a la audiencia en función de los contenidos de la página en la que se inserta, así como ganar valor ańadido absorbiendo por metonimia el valor atribuido a los mismos, pero con la ventaja de poder afinar mucho mejor a la hora seleccionar a su público objetivo dada la gran variedad de páginas. El estudio (Online Publishers Association 2003) demuestra (algo que daba por sentado el patrocinio) que influye más el lugar donde se inserta el banner que la frecuencia de impactos. Este modo de segmentar a la audiencia sin embargo todavía casi no se emplea: gran parte de los banners se colocan en la portada de los periódicos de mayor tirada o en los portales más frecuentados (estos últimos acaparan el $41 \%$ de la publicidad online, Agemdi, 2002), lugares de paso de mucha gente indiferenciada. La única segmentación que se lleva a cabo es a través de las palabras clave del propio banner. Nos encontramos en la misma situación que en los medios de comunica- 
ción masivos, matando moscas a cañonazos -y muy lejos de la segmentación a partir de los centros de interés propuesta por Isabel de Salas (1999:183-188)-. Esto quizás se deba a que hoy por hoy, la audiencia en Internet, aún de la página más visitada, resulta ridícula en comparación con la que consigue cualquier anuncio de radio o televisión.

Los banners han evolucionado a una velocidad vertiginosa en los últimos años existiendo en la actualidad gran variedad de formatos. Con respecto al tamańo del encuadre de los banners fijos (One Click y Rich Media) se han generalizado los tamaños de $460 \times 60$ pixeles (utilizado por el $50 \%$ de los anunciantes), que es esa tira ancha que aparece normalmente centrada debajo de la cabecera de la página; los llamados rascacielos de $120 \times 600$ o $120 \times 240$ pixeles, notmalmente ubicado en la derecha de la página; los rectángulares de $234 \times 60$ pixeles; los de formato cuadrado de $125 \times 125$ pixeles; y los más pequeños también llamados botones de $120 \times 60$, $120 \times 90$ y $88 \times 31$ pixeles. Por otra parte pueden ser de encuadre estable o desplegable (que se agrandan ante la presencia del ratón utilizando la tecnología del Rich Media). Los banners pueden remitir a través del click through a la página corporativa sede o a un microsite. Un microsite es una página web más específica y menos extensa que puede pender del directorio raíz de la página corporativa o pender de otra web de contenidos relacionados que lo acoge mediante la fórmula del patrocinio o incluso puede tener LRU propia. Las acciones publicitarias Beyond the Banner incluyen ventanas flotantes, que son ventanas de distinto tamaño que se superponen delante (pop ups) o detrás (pop under) de la página visitada, pueden activarse solas o ir asociadas a un banner y activarse cuando se pasa el cursor por encima. Los instertitiales pueden aparecer a pantalla completa activándose sólo en el momento de espera y tránsito de una página a otra. Otras acciones publicitarias Beyond the Banner incluso pueden no limitarse a un encuadre o ventana. Los layers son imágenes superpuestas que pueden desplazarse en cualquier dirección por la página, las moscas son logotipos super- 
puestos a las páginas o también se puede transformar y animar el icono del puntero con distintos dibujos o logotipos. Todos estos formatos pueden utilizar el dibujo o la reproducción fotográfica, y a su vez pueden incluir textos o imágenes estáticas o animadas así como interactividad. Según la forma y el momento de descargar hay anuncios que se descargan antes que la página, otros al mismo tiempo y otros después.

Los banners, que disponen de muy poco tiempo y espacio, y cuya función inicial era redireccionar al usuario hacia la página sede donde encontraría información detallada, han evolucionado muy pronto hacia los mensajes sorprendentes y seductores (más teasing y menos información).

\section{Actitud del internauta ante la publicidad en red}

Según el estudio "La actitud del usuario ante la publicidad online", elaborado conjuntamente por Sigma Dos Interactiva y la revista Baquía (Baquia Inteligencia 2003), la actitud del internauta español frente a la publicidad online es mucho más negativa que la del espectador de medios de comunicación masiva. Según el citado estudio el $38,2 \%$ de los internautas espańoles encuestados consideran que la publicidad en línea es mala o muy mala, el 39,5\% regular, y sólo para el 19,7\% es "muy buena" o "buena". Al segmentar según el tiempo que llevan utilizando Internet, encontramos que son los usuarios más veteranos los que muestran mayor rechazo: casi la mitad la consideran mala o muy mala, y sólo el 17\% muestra una actitud favorable. También más críticos son los mayores de 24 años. Esto contrasta con la actitud de los espectadores ante la publicidad televisiva que ha conseguido convertirse en un objeto de consumo por su valor simbólico al margen de su efectividad para producir ventas, y seduce en cuanto a tal incluso al público no objetivo: un inteligente o llamativo espot de una compañía aérea puede interesar por ejemplo tanto a la clase baja como a los niños que no usan ni van usar dichos servicios. La creatividad y sutileza de algunas campañas televisivas las ha elevado a la categoría de arte 
y convertido en objetos de culto entre los más jóvenes, asentando el liberalismo muy profundamente en sus esquemas mentales (León 1996: 29-61). Algunas marcas han conseguido incluso convertirse en detentoras de valores sociales que antaño sólo se vehiculaban a través de instituciones benéficas o públicas. Los jóvenes se adhieren a los eslóganes pseudo contestatarios de Liberto, Diesel o Lois -"con lo que las energías transgresoras juveniles se domestican siguiendo el principio de las vacunas" (León 2001: 120)- o se dejan arrastrar por la pasión por el fútbol o el atletismo que propugnan sus ídolos incontestados: Cocacola o Nike, con el mismo entusiasmo y convicción con el que en los años setenta se manifestaban en defensa de las libertades.

Pero muy diferente es la actitud del internauta. Según el citado estudio, los motivos de este rechazo son claros. La respuesta es unánime: el $94{ }^{\prime} 4 \%$ de los internautas considera que la publicidad online es molesta y estorba en la navegación, el $73 \%$ que es invasora y sólo un $17,8 \%$ considera que la publicidad online es poco original o creativa. Este espaldarazo a las prácticas publicitarias más agresivas e intrusivas (que se admiten en televisión) puede deberse a los precedentes que sentó Internet en sus orígenes universitarios, con una oferta centrada en la información de calidad, sin entretenimiento, distracciones ni retrasos. Especialmente polémicos son los pop up y layers que además de impedir ver la información solicitada, algunos son incluso anti-interactivos: te reenvían a la página corporativa cuando precisamente expresas tu desinterés al intentar cerrar la ventana, frustrando así el deseo de elegir, dominar e interactuar del internauta. Tampoco son apreciados los banners con destellos luminosos. Aunque es cierto que la imagen en movimiento llama poderosamente la atención y ésta es una fórmula muy sencilla de crear un banner poco pesado, puede provocar un efecto contraproducente porque resultan extremadamente molestos para leer la página. Las imágenes pesadas que bajan antes o al mismo tiempo que la página, aunque menos, también son rechazadas por ralentizar la transmisión. 


\section{Interesantes novedades discursivas y tecnológicas en las webs comerciales y las acciones publicitarias}

A la vista de las páginas webs y acciones publicitarias seleccionadas por la 18 edición del Festival publicitario Iberoamericano El Sol (lista corta) ${ }^{1}$ : advertimos que se ha desarrollado sobre todo la imagen fotográfica, la imagen en movimiento (animaciones y vídeos) e introducido tímidamente el audio y la interactividad. Sin embargo en la actualidad, cuando todavía no se ha generalizado la banda ancha, si dejamos a un lado la originalidad, espectacularidad y creatividad y nos centramos en su adecuación a las condiciones del nuevo medio, uno de los mayores problemas que plantean los banners y páginas webs, es la cantidad de bites que ocupan, que se traduce en tiempo de descarga y son precisamente los que incorporan éstos elementos los que más memoria ocupan. Los documentos más pesados son aquellos que reproducen vídeo, le siguen las imágenes fijas de calidad fotográfica. Más ligeras son las animaciones simples y los documentos sonoros.

Gran parte de las páginas webs comerciales son excesivamente pesadas, en unos casos debido a una elaborada animación interactiva: como en Larios Dry ("Larios Dry Web") u Orbital ("Orbital" web corporativa); en otros debido al abuso de la imagen con calidad fotográfica: como en Sáez Merino Caroche ("Life is chic", web promocional), Sáez Merino Cimarrón ("Un espíritu nómada", promocional), BMW ("BMW Coupé Diesel Fotocopiadora" Campañas integradas), Audi ("Audi Cabrio", "A8" promocionales) y muchas otras; o incluso por la incorporación de la imagen en movimiento: el vídeo de Cruz Roja España ("Tú también lo haces", Beyond the Banner) o el de Jarabe de Palo ("Bonito" promocional) además con un audio excesivamente rico, etc. Destacarían por su ligereza, efec-

\footnotetext{
1 Todos los anuncios en soportes interactivos citados en este artículo han participado en la 18 edición del Festival Publicitario Iberoamericano de El Sol y son consultables en la lista corta de anuncios destacados que presenta el Festival en su página web. Se aludirá a ellos por el nombre de la marca anunciante y el nombre de la pieza con el que se inscribieron en el Festival.
} 
tividad y sencillez las siguientes webs: la página promocional Hotel del Norte ("Hotel del Norte") y la de Greenpeace "El bosque primario" (http://161.58.169.118/greenpeacez/flash.html) por su moderada combinación de calidad fotográfica e interactividad; el microsite de BBVA ("Hipoteca fácil" campañas integradas) por la efectividad y sencillez de su animación; y la página creación de comunidad de Mahou ("¿Quien mató a JFK?") por su ligereza e interesante uso de la interactividad.

Dentro de las páginas webs existen muy diversos grados de interactividad, desde el más simple que consiste en pinchar en un punto de la imagen para acceder a otra página o ventana con nueva información (escrita o visual), hasta la incorporación de juegos interactivos donde la capacidad de selección y las variables son muchísimo más amplias. Recurren a ellos las páginas de empresas de productos económicos de consumo habitual como Mahou, Smirnoff, Larios Dry o San Miguel. "Smirnoff Ingenio" (promocional de Diageo) plantea unas pruebas de ingenio para que el usuario pueda acceder a una discoteca. Presentando un único decorado interactúa con el usuario básicamente a través del texto escrito: una serie de preguntas realizadas por el portero de la disco que se contestan eligiendo entre una serie limitada de opciones. Una vez finalizada la prueba el resultado es comunicado en texto escrito y acompañado con una muy leve animación del portero. "San Miguel City" (generación de comunidad) ofrece al internauta la posibilidad de elegir su personaje entre las posibilidades de un menú relativamente cerrado, y permite que el internauta interactúe mediante animación: tiene a su disposición una serie de gestos e itinerarios, así como interactúan mediante animaciones los demás personajes y usuarios. Entre una elección y otra se introducen animaciones preprogramadas que en la mayoría de los casos no varían en función de la elección del usuario: trayecto al hotel, etc. A pesar de que el planteamiento es bueno el juego acaba resultando aburrido porque es enormemente lento para los estándares de velocidad de transmisión actual. "Larios Dry Web" en su fiesta desarrolla todavía más 
ampliamente la interactividad mediante animaciones. Los decorados cambian a medida que se desplaza el individuo-usuario y los otros personajes de animación interactúan con el usuario reaccionando a su presencia. Sin embargo al recorrido le falta un objetivo y mete con calzador información sobre el producto totalmente irrelevante. La página es extraordinariamente pesada y desesperante. "Quien Mató a JFK" de Mahou por su parte plantea una estrategia mucho más elaborada a partir del planteamiento de un juego interactivo de investigación con mucho humor y genuino sabor español, al estilo Almodóvar. Construye un relato interactivo en el que el internauta es un investigador que debe descubrir quien es el asesino de un torero que ha sido encontrado muerto en una habitación de hotel con dos banderillas clavadas en la espalda. Es relativamente poco pesado para la interactividad que plantea. No se complica con suntuosos decorados y animaciones y se centra en la búsqueda de una respuesta inteligente. La actividad del usuario consiste en la observación de una foto fija del escenario del crimen de la que puede recoger pruebas, mirar con atención (con lupa), analizar huellas digitales, sangre y otros líquidos, además de preguntarle a personajes del más allá. Las respuestas a las acciones del usuario, resultado de los análisis etc., no implican animaciones sino textos escritos que aparecen en la pantalla o pasan a engrosar el dossier, una carpeta con documentación escrita que se va ampliando a medida que va avanzando la investigación. Concluimos pues con la constatación de que dada la velocidad actual estándar de transmisión no resulta adecuado introducir interacción que implique elaboradas animaciones. Otras webs ofrecen la posibilidad de interactuar (intervenir) a nivel social (aunque sin ninguna consecuencia, lógicamente): Diesel "LiveAction" espera que el joven se queje (del lo que sea) aporreando el ordenador, y Liberto Jeans "Open your Mind" propone que el usuario se exprese decidiendo a qué político hay que regalarte un liberto (suponiendo que ello hará que su visión de mundo se parezca más a la de los jóvenes: "¿Que se vuelvan todavía más conservadores y supuestamente apolíticos?"). 
En los demás casos la interactividad se reduce a pinchar en los diferentes textos o iconos que nos reenvían a nuevas imágenes o textos.

Por otra parte también muchas son las webs que desafortunadamente han recurrido a la capacidad de seducción de las imágenes fotográficas o del vídeo, con el agravante de que no presentan sólo una sino una secuencia de imágenes y en muchos casos acompañada de un audio excesiva e innecesariamente rico: casos de Audi Cabrio, BMW Coupé, Renault Megane, Cimarrón, Caroche etc. Un uso más moderado y efectivo realiza Greenpeace en su defensa del bosque primario. En un fichero no excesivamente pesado simula una panorámica de 360 grados en el interior de un bosque. Introduce cierto grado de interacción puesto que la cámara se mueve sin perder realismo en la dirección y a la velocidad que marca el ratón del usuario e introduce al fondo de la misma mensajes de texto que se agrandan al pasar el cursor por encima. Evidentemente no se trata de imagen vídeo pero el realismo se refuerza con el sonido del bosque. También moderado es el uso de la imagen fotográfica que realiza Hotel del Norte donde se incluyen tan sólo las vistas más relevantes del lugar a tamańo moderado, completadas con información en texto escrito y una muy poco pesada interactividad que consiste en variar la luminosidad de la vista en función de la hora y época del año seleccionada por el visitante.

Pero qué duda cabe que las soluciones más innovadoras, ingeniosas y mejor adaptadas al nuevo medio han venido de la mano de las acciones publicitarias: banners, banners enriquecidos, más allá del banner y e-mail marketing. Internet es un medio publicitario muy joven y con mucho potencial que todavía está explorando sus posibilidades técnicas. El reducido espacio y tiempo disponible ha sido un gran acicate para la creatividad. El banner plantea los mismos problemas que el espot televisivo, la necesidad de transmitir un mensaje seductor y atractivo en el menor tiempo posible, pero en este caso no por el elevado coste económico de su elaboración y emisión, sino porque es el usuario quien decide qué quiere ver y puede abandonarnos antes de que el banner haya tenido tiempo de 
bajar. Es cierto que aquellas acciones publicitarias que incorporan imagen en color, movimiento (tanto interno como externo), sonido o interactividad (llámense Rich Media, Beyond the Banner, e-mail marketing) son las que más poderosamente atraen la atención sobre todo si pensamos que una página web no comercial es básicamente estática, muda, poco interactiva y se compone en gran medida de texto. De hecho el estudio realizado por Doubleclick (2002) subraya un estancamiento de la efectividad e inversión del banners tradicional y un aumento más que significativo del Rich Media y Beyond the Banner.

Aunque estamos en plena etapa de búsqueda y experimentación ya se advierten en algunos banners relativamente ligeros, una ingeniosa explotación del valor semántico del propio formato. El banner (Rich Media) de Amigos de la tierra, titulado "Rasca rasca", que solicita voluntarios para limpiar el chapapote, aplica de forma muy inteligente y coherente la interactividad. Presenta un banner manchado de negro que a medida que se pasa el cursor va rascando el negro y descubriendo el cartel. El ruido característico acompaña la acción del usuario. Otro caso interesante de interactividad perfectamente integrada en el mensaje es el banner interactivo (Rich Media) titulado "Desestresante interactivo" de la Operadora de viajes Grupos Norte Tour. Un jugador de golf animado reacciona ante la intensidad del clic lanzando la pelota y diagnosticando estrés y la necesidad de unas vacaciones en un campo de golf del norte. Amnistía Internacional en su anuncio "No Items" (Beyond the Banner) contra la guerra de Irak, se sirve de la interactividad que plantea el propio ordenador a través de los iconos típicos de las carpetas del Mackintosh para representar las distintas ciudades de Irak y en su interior subcarpetas con el nombre de Población, Escuelas, Hospitales. Cuando el usuario intenta abrirlas pulsando el ratón aparece el clásico mensaje de: "No Items" para representar las consecuencias de la guerra. Intermon (Beyond the Banner) en su pieza "Haz algo con seis euros" precisamente se burla de la inutilidad de muchos juegos interactivos. Insta al visitante para que intente colo- 
car los 6 euros en triángulo, círculo etc., para acabar proponiendo, dada su inutilidad, que se usen para salvar vidas en el Tercer Mundo. Por último "Interactividad emocional" de Orbital (e-mail marketing), es un e-mail, que en sus diferentes versiones, caricia, abrazo, induce al usuario a acariciar o abrazar imágenes con el ratón para expresar su amor a la persona destinataria. También le saca rendimiento Amnistía Internacional a las supuestas deficiencias de Internet para vehicular narraciones audiovisuales en su pieza "Psiquiátrico" (Rich Media) en defensa de los derechos de los homosexuales. La pieza consta de una serie de fotos fijas. Aunque constituyen una secuencia que relata una acción que se desarrolla en el tiempo, las elipsis entre una y otra, así como la ausencia de movimiento y sonido, juega con la ambivalencia de su significado. Si en un primer momento interpretamos una relación lésbica entre dos mujeres, al final descubrimos que se trata del internamiento forzoso en un psiquiátrico de una mujer por seguir sus tendencias sexuales.

"Hipoteca fácil" del BBVA (campañas integradas) o "La lata" de Cocacola (campañas integradas) aprovechan el valor semántico del desplegable. Cocacola utiliza la reducción inicial del banner para introducir un golpe de guión. El banner aparece en un primer momento en el formato estándar de $460 \times 60$ pixeles y se representa lo que parece ser una simulación de los primeros juegos de ordenador de tenis en el que moviendo el ratón le das a la pelota con la diferencia de que en este caso se trata de una lata de Cocacola.

Cuando el banner se despliega hacía abajo descubrimos que las dos rayitas en realidad representan a dos jugadores que pelotean delante de una portería de fútbol y es el usuario el que moviendo el ratón actúa de portero. El banner de la hipoteca del BBVA representa la flexibilidad de la hipoteca fácil a través de un banner deformable y desplegable. Un individuo en animación se encuentra sentado y encerrado en un banner cuadrado excesivamente pequeño para su tamańo, pidiendo ayuda para salir y dando patadas a los márgenes del encuadre que se deforman con la presión. Cuando se 
pasa el ratón por encima el banner se hace más grande de forma que el individuo sin cambiar de tamaño se puede incorporar. En otra interesante versión el individuo se acuclilla en dirección al margen del banner y salta a otro banner vacío surgido con pop up y a su vez desplegable.

Una ingeniosa innovación en el uso del sonido la encontramos en otro banner, "Electrocardiograma" (Rich Media) de tamaño estándar y con golpe de guión de Médicos sin Fronteras. En él aparece en un monitor la señal del funcionamiento del corazón mientras oímos el pitido de la regularidad de las constantes vitales. Cuando el ratón recorre el banner aparece el mensaje: "extralife" simulando los juegos de ordenador. Cuando pulsamos para ir a la web madre realizamos el salto con raccord de sonido sin dejar de oír en ningún momento el pitido de las constantes vitales, manteniendo la tensión y la sensación de urgencia de las donaciones así como indicando que la partida no ha llegado a su fin, todavía es posible salvar alguna vida, conseguir una "extralife" con la donación efectiva. Interesante también es el caso del banner (Rich Media) titulado "Interferencias" del móvil Eresmas. Sonido, imagen y contexto se integran a la perfección. El audio reproduce el sonido de las interferencias que provoca la proximidad de un móvil que va a sonar cerca de una pantalla de ordenador, al tiempo que las vibraciones e interferencias recorren y hacen temblar visualmente coda la página web y no sólo el banner. Simpáticos también resultan la serie de banner (Rich Media) de Yahoo, "Yahoo3" y "Yahoo4" que publicitan con humor sus comunidades y Chats mediante unas simples animaciones de unos pececitos que se mueven y cantan al ritmo de la música.

Los vídeos "Reno" (de J. Walter Thompson Argentina, Rich Media) y "Built to resist" (de Eastpack, e-mail marketing) o la campaña "Tú también los haces" contra los prejuicios raciales en el empleo de inmigrantes de Cruz Roja (Beyond the Banner) aunque interesantes como piezas audiovisuales -serían buenos espots televisivos-, son un fracaso en el medio en el que se insertan. 
5. Tendencias del discurso publicitario: hacia el patrocinio y el banner narrativo audiovisual

La evolución de la audiencia y de la implantación de la banda ancha marcará la futura evolución de la publicidad en Internet. La creciente disparidad entre las clases sociales, donde sólo un 3'9\% de los hogares españoles tiene banda ancha mientras que un nutrido $33 \%$ no tiene ni siquiera coche o vídeo, junto a la débil y lenta inversión pública en la enseñanza de las nuevas tecnologías -0 '4\% del PIB, muy inferior a la media europea que está en el 0'7\% (CEPREDE 2003: 4) - no parece augurar una rápida generalización del uso Internet.

Por otra parte la prematura incorporación de la imagen fotográfica y en movimiento, así como la interactividad en las páginas webs, ha provocado que una de las quejas más frecuentes de los internautas avezados sea la lentitud de las comunicaciones, por lo que parece previsible que se implantará mucho antes la banda ancha entre el 19\% que ya tiene Internet, que se generalice su uso entre las clases media y baja. Es probable que en breve plazo la conexión a velocidad regular llegue al 36'3\% que hoy dispone de ordenador, al tiempo que la clase alta y media alta acceden a la banda ancha y así se mantenga durante bastante tiempo (hasta que se desarrolle la televisión interactiva). La publicidad tendrá que adaptarse a estas dos velocidades. Por un lado proliferarán las páginas webs, bastante elaboradas visual e interactivamente, de anunciantes de productos selectos y minoritarios, que colocarán sus discretos banners en páginas con alto valor informativo; y por otro se multiplicarán los banners y microsites poco pesados, más agresivos e invasivos, de productos de consumo habitual y masivo, colocados en lugares de mucho tránsito (básicamente de contenido lúdico), que no siempre remitirán a la página sede.

La actual incongruencia entre los contenidos de las páginas webs y los intereses de su audiencia mayoritaria, posiblemente desencadenará una masiva expansión del patrocinio como prevé Armstrong (2002: 101). En primer lugar pese a la significativa 
presencia de los jóvenes en Internet que demandan páginas de entretenimiento apenas si hay contenidos de este tipo y se da la paradoja de que a pesar de que se prevé que se incrementará a mayor velocidad por la franja de edad inferior, existen poquísimas páginas webs dedicadas a los niños. En segundo lugar, a pesar de que los usuarios adultos tienen en su mayoría un nivel de formación medio alto y frecuentan la red en busca de información y servicios, existen muy pocas páginas con información de calidad: me refiero a bases de datos, información institucional, publicaciones científicas etc., que precisamente encontraron en Internet su medio ideal (cuando todavía era un medio universitario) debido a que son consultadas esporádicamente y por un número reducido de personas dispersas geográficamente.

Las pocas que hay son en su mayoría suministradas por instituciones públicas y carecen de publicidad, o son consultables previo pago.

Estas páginas de costosa elaboración y mantenimiento (sean de entretenimiento o de información de calidad) son las que pueden convertir Internet en el medio de comunicación por excelencia. La fórmula del patrocinio podría ayudar a superar este impas, convirtiendo Internet en un medio al alcance de todos y beneficiarse de los réditos que esta situación puede ofrecer a la publicidad (especialmente para los anunciantes de productos baratos o de consumo habitual, adviértase que en el 2002 la inversión publicitaria en Internet en España no supuso ni el 1\% del total de la inversión en medios convencionales (Infoadex 2003).

Algunos anunciantes ya se han lanzado a ofrecer aquellos contenidos, tan demandados, que no ofrece la red: el entretenimiento que ofrecen los portales o las webs promocionales y de generación de comunidad con sus juegos interactivos. Sin embargo, esta práctica no es sostenible a largo plazo. Su proliferación y la presión de la competencia les obligará a mejorar y renovar constantemente los juegos interactivos, que serán cada vez más elaborados y sofisticados, requiriendo grandes inversiones en investigación para su ela- 
boración y puesta al día. Inversión que sólo se podrán permitir en todo caso las grandes marcas. Es más previsible que el mercado se especialice y sean las empresas de juegos interactivos en red las que se dediquen a tales menesteres subvencionadas por distintos anunciantes interesados en un mismo segmento.

La propia red ya implica una selección inicial del público objetivo bastante interesante para gran parte de los anunciantes que probablemente se mantenga diferenciada con el establecimiento de las dos velocidades: los usuarios de la red de hoy y de la conexión rápida de mañana son y serán de clase media alta y alta y relativamente joven. Este público, sobre todo el adulto, es especialmente interesante para los anunciantes de productos de costosa financiación: que podrían patrocinar portales con bases de datos y documentación sobre investigaciones sociales, económicas, médicas, nuevas tecnologías, webs institucionales, portales de jazz o guías interactivas con rutas con encanto donde poder colocar banners de restaurantes, hoteles o productos de denominación de origen de cada zona etc., pero también puede ser una vía interesante para los productos de consumo habitual si lo que se pretende es que la clase media se convierta en modelo a imitar.

Si el público objetivo es juvenil, se puede copatrocinar un portal o página web especializada por ejemplo en un tipo música, que incorpore bases de datos con autores, canciones, bibliografías, o un portal sobre deportes de riesgo o un Chat. La alarma social que se ha creado a partir del descubrimiento de la existencia de pederastas en los Chat juveniles podría impulsar a los anunciantes a rentabilizar publicitariamente esta práctica y patrocinar Chat seguros dirigidos a los niños y jóvenes, en los que por ejemplo los usuarios se tengan que identificar, ante la propia empresa aunque puedan seguir en el anonimato frente a los otros usuarios, y se controle y monitorice la información transmitida de alguna manera, de forma que se aseguren que la información trasmitida no es nociva para este colectivo y que los delitos no quedarán impunes tras el anonimato. 
Con respecto a los nińos podemos imaginar la rentabilidad que se puede obtener del copatrocinio de páginas webs con juegos interactivos educativos (hoy prácticamente inexistentes), en las que se podrían publicitar juguetes, libros juveniles, ropa de nińo, CD música, DVD, videojuegos, refrescos, bollería etc.

Los contenidos de entretenimiento destinados en un primer momento a atraer al público juvenil de la clase media y alta, posteriormente atraerá a la clase baja que estará dispuesta a consumir publicidad a cambio de juegos interactivos interesantes. Es probable entonces que los productos de consumo habitual se lancen en masa a anunciarse en la red, así como que aparezcan, bien impulsados por las administraciones locales o por los propios empresarios, portales locales que a su vez atraigan a los pequeños empresarios locales.

En principio la red permite segmentar hasta el infinito la audiencia permitiendo la coexistencia de páginas webs selectas y banners de productos muy especializados y exclusivos de consumo minoritario con otras más generalistas con banners de productos de consumo habitual y mayoritario, sin embargo la experiencia nos dice que probablemente la audiencia y con ella la publicidad acabe concentrándose en un número reducido de portales y s. Si miramos el caso de la radio nos percatamos que a pesar del gran número de estaciones existentes la mayor parte de la audiencia se concentra en sólo cuatro.

Si la ratio del click-throught desciende a la misma velocidad que hasta ahora (y como era de esperar) es previsible que las inversiones publicitarias se centren además de en los patrocinios en los banners incluyo aquí el one-click, rich media y beyond de banner).

Aunque la tecnología permite la utilización del audio, de la animación, de la calidad fotográfica y del vídeo, con más o menos grados de interactividad, no todas estas posibilidades se desarrollarán en la misma medida, debido precisamente a ese largo periodo de coexistencia de las dos velocidades en Internet. Los banners que quieran dirigirse a una audiencia amplia no puede pesar más de lo 
que pesan en la actualidad (ya hemos señalado que en muchos casos es incluso excesivo), sobre todo si se colocan en lugares de paso, por lo que no podrá evolucionar hacía una mayor complejidad visual (uso de la imagen fotográfica y el vídeo), puesto que eso supondría excesivo peso pero sin embargo sí puede evolucionar hacia una mayor utilización del audio, de las animaciones y de interactividad, así como ampliar la cantidad de información del mensaje explotando la secuencialización de la información en una serie de banners colocados en diferentes páginas de un mismo site siguiendo, mediante cookies, el recorrido del internauta. Esto permitirá el desarrollo del relato audiovisual en línea, que ha estado asombrosamente ausente -sobre todo si tenemos en cuenta que los espots televisivos tienden cada vez más a contar historias (Rausell 2003b)-. Hablamos de discurso "audiovisual" cuando se utilizan conjuntamente el audio y la imagen, y será "relato" audiovisual si la secuencia de imágenes (sean fijas o en movimiento) cuentan una microhistoria, una serie de acontecimientos relacionados causalmente y que tienen lugar en un tiempo y un espacio.

Aunque sin explotar las posibilidades del audio un ejemplo de narración visual con animación y con muy débil interactividad lo encontramos en las distintas versiones de la hipoteca fácil del BBVA. Un individuo animado encerrado en un banner cuadrado golpea el mismo y pide mediante un globo de texto que le ayudemos a salir. Cuando pasamos el cursor por encima el banner se hace más grande y el individuo se incorpora, en otra versión consigue saltar a otro banner vacío que también se despliega y le permite incorporarse.

Evidentemente la imagen en movimiento (sea animación o vídeo) que describe una acción posee ya un cierto grado de narratividad pero no es la única forma posible. Otro ejemplo de micronarración visual (en este caso construida mediante una serie de fotos fijas) que no utiliza la interactividad la encontramos en la pieza "Psiquiátrico" de Amnistía Internacional donde la secuencia de fotos fijas que parece representar el inicio de una relación sexual 
lésbica finalmente resulta que describe el proceso de amordazamiento por parte de la enfermera de una mujer homosexual internada forzosamente por dicho motivo en un hospital psiquiátrico.

Estas micronarraciones audiovisuales que requieren un orden y tiempo de emisión preestablecido y determinado, normalmente de mayor duración, deberían, para ser efectivas, situarse en páginas que requieran cierto tiempo de lectura, pero hay otras alternativas. En los dos casos anteriores nos encontramos con micronarraciones que se desarrollan en un único banner sin embargo podrían ser continuadas o divididas en diferentes banners de diferentes páginas de un mismo site. El banner de BBVA enlaza con la página sede donde el mismo individuo, ahora ya en la casa que ha conseguido gracias al crédito, empuja y desplaza los bordes de la ventana agrandando el banner hasta conseguir el tamaño de la vivienda que desea, como reza el eslogan. El mismo nexo discursivo establece el banner de Médicos sin Fronteras con su página sede. Con raccord de sonido el internauta, supuesto jugador de un juego de ordenador continua la partida en la página sede, y está acabará cuando el usuario haya efectuado la donación y conseguido una extralife. Esta secuencialización del discurso o narración en diferentes páginas que ya practican algunos banners con sus páginas sede podría sin embargo producirse con banners ubicados en las siguientes páginas que visita el usuario en el mismo directorio raíz. La relación entre la primera parte del relato y las siguientes en lugar de entablarse a través del clic se realizaría a través de cookies. Para ello un mismo anunciante tendría que comprar distintos espacios en diferentes páginas del mismo directorio raíz, lo ideal es que estuvieran situados en la misma parte de las diferentes páginas para no desorientar al espectador y que distintos anuncios rotaran en cada uno de esos espacios. Así el inicio de la historia podría comenzar en la portada de un periódico, por ejemplo, y cuando saltamos a internacional se nos enviara una cookie que verificará que hemos visto la primera parte del relato, para así lanzar, entre sus diferentes anuncios en rotación, la segunda parte del anuncio que hemos visionado, o la 
primera u otro anuncio en su defecto. Para ello haría falta que los diferentes medios, portales y páginas s estudiaran el tiempo medio de lectura de sus páginas. Las posibilidades publicitarias del relato audiovisual y del relato audiovisual interactivo tanto en las páginas como en los banners constituyen todo un campo todavía por explorar.

\section{REFERENCIAS BIBLIOGRÁFICAS}

AEAP Asociación Española de Agencias de Publicidad (2003): Palmarés del 18 Festival publicitario Iberoamericano. (Disponible 27/08/2003 en www. Elsolfestival.com/palmarés2003).

AEAP Asociación Española de Agencias de Publicidad (2003): Lista corta de soportes interactivos del 18 Festival publicitario Ib eroamericano. (Disponible 27/08/2003 en www. Elsolfestival.com).

AGEMDI Asociación de Agencias de Marketing Directo e Interactivo (2002): III Estudio sobre el marketing y la publicidad en internet. (Disponible 27/08/2003 en www.agemdi.org).

AIMC/EGM Asociación para la Investigación de medios de comunicación/Estudio General de Medios (2003): Marco general de los medios en España, Madrid, AIMC.(Disponible 27/08/2003 en www.aimc.es).

AIMC/EGM (2003): Audiencia de internet en Abril/Mayo del 2003, Madrid, AIMC. (Disponible 27/08/2003 en www.aimc.es).

ARMSTRONG, Steven (2002): La publicidad en internet, Bilbao, Ediciones Deusto

BAQUÍA INTELIGENCIA (2003): "¿Qué opina el internauta espańol de la publicidad online?" en Baquia $29 / 01 / 2003$. (Disponible 27/08/2003 en http://www.baquia.com/com// $20030129 /$ bre00004.html).

BARCELONA ACTIVA S.A (2002): "El comercio electrónico en el mercado actual", en Barcelona Activa.net, Barcelona, Barcelona Activa S.A. (Disponible 27/08/2003 en www.barcelonaactiva.net). 
CEPREDE (Centro de Predicción Económica de la Facultad de CCEE y EE de la Universidad Autónoma de Madrid (2003): Informe mensual sobre penetración de la nueva económica en $N$ economia no 12, 2003, Madrid, Universidad Autónoma de Madrid. (Disponible 27/08/2003 en www.n-economia.com).

DE SALAS NESTARES, Ma Isabel (1999): La comunicación publicitaria interactiva en internet, Valencia, Fundación Universitaria San Pablo CEU.

DOUBLECLICK INC (2002): Doubleclick Q3 Ad Serving Trend Report, DoubleClick Inc, diciembre 2002. (Disponible 27/8/2003 en www.doubleclick.net).

INFOADEX (2003): Resumen del Estudio Infoadex de la inversión publicitaria en España 2003. (Disponible 27/08/2003 en http://www.infoadex.es/noticias/ficheros/resumen2003.PDF).

LEÓN, José Luis (1996): Los efectos de la publicidad, Barcelona, Ariel.

LEÓN, José Luis (2001): Mitoanálisis de la publicidad, Barcelona, Ariel.

ONLINE PUBLISHER ASSOCIATION (2003): The Impact of Audience Affinity on Advertising Performance, junio 30. (Disponible 27/08/2003 en www.online-publishers.org).

RAUSELL KÖSTER, Claudia y Pau (2003): "Red: mercado y publicidad", en J. M Bernardo, Gavaldà, Pellisser, El debate sobre la cultura de la imagen, Valencia, Nau Llibres y Universitat de València.

RAUSELL KÖSTER, Claudia (en prensa): "La comunicación publicitaria: Tendencias narrativas y discursivas en los espots publicitarios", en Actas del IV Foro de Investigación en comunicación: La comunicación: industria, conocimiento y profesión, Madrid, Universidad Complutense de Madrid.

TELEFÓNICA (2002): La sociedad de la información en España 2002. Presente y perspectivas, Madrid, Telefónica. (Disponible 
27/08/2003 en: www.telefónica.es/Sociedaddelainformacion /España2002). 